\title{
PP014 - Métodos subsidiários para o diagnóstico da Leishmaniose tegumentar americana (LTA): comparação dos resultados do seqüenciamento de DNA e da PCR-RFLP para determinação da espécie de leishmania em amostras cutâneo-mucosas" Subsidiary methods for the diagnosis of American tegumentar leishmaniasis (ATL): comparison of sequencing of DNA and PCR-RFLP for identification of leishmania species in skin samples.
}

\author{
Flávio C. Barbosa Garcia ${ }^{1}$ \\ Ângela C. Rapela Medeiros ${ }^{4}$ \\ Sandra Silva Rodrigues dos Santos ${ }^{2}$ \\ Maria Fernanda Chociay ${ }^{3}$
}

\begin{abstract}
Resumo: Fundamentos - Métodos moleculares têm-se mostrados mais eficazes para o diagnóstico da LTA. OBJETIVOS - Comparar os resultados da intradermorreação de Montenegro (IRM), presença de leishmania em biópsia $(\mathrm{Bc})$, reação de imunofluorescência indireta (Rifi), seqüenciamento de DNA e PCR-RFLP (-restriction fragment lenght polymorphism) para o diagnóstico da LTA.

MÉTODOs - Foram estudados 152 pacientes com LTA. Para a PCR em Bc, utilizaram-se primers específicos para seqüência de 120bp do kDNA do minicírculo comum a todas as espécies de leishmanias. O produto da PCR, utilizado para seqüenciamento e para restrição enzimática com Hae III, foi comparado às culturas $L$. (L.) amazonensis $\mathrm{e}$ L. (V.) braziliensis.

ResulTADOS - Houve predomínio do sexo masculino (75\%), da cor branca (80\%) e da profissão urbana (48\%). A idade variou de três a 77 anos, com 56,5\% entre 21 e 50 anos. 65,8\% eram do Estado de São Paulo, prevalecendo a forma cutânea (79,6\%). A IRM foi positiva em 73,4\%, e a Rifi em 59,7\%, enquanto a Bc evidenciou presença de leishmania em 30,6\%. A PCR foi positiva em 81,6\%, e a PCR-RFLP identificou $L$. (V) braziliensis como espécie predominante (66\%), o que também ocorreu com o seqüenciamento. Comparando PCR-RFLP e seqüenciamento, houve $61 \%$ de concordância entre os resultados, mostrando significância da PCR-RFLP para L. (V.) braziliensis.

CONCLUSÕES - A IRM e a PCR foram estatisticamente equivalentes como métodos subsidiários para o diagnóstico da LTA, a PCR-RFLP e o seqüenciamento também o foram na identificação das espécies de leishmania, o primeiro apresentando menores custo e tempo de execução comparado ao seqüenciamento de DNA.

Palavras-chave: DNA; Leishmaniose tegumentar; Reação em cadeia da polimerase
\end{abstract}

\begin{abstract}
BACKGROUND - ATL is endemic in Brazil, and molecular methods have been shown more effective for its diagnosis.

OBJECTIES - Our purpose was to compare the results of Montenegro's skin reaction (MR), presence of leishmania in skin biopsy (Bx), indirect immunofluorescence (IIF) for leishmania in sera samples, PCR, sequencing of DNA and PCRRFLP (polymerase chain reaction-restriction fragment length polymorphism) as subsidiary exams for ATL diagnose. METHODS - 152 patients were studied, with accomplishment of MR, Bx, IIF and PCR for leishmania in skin samples. For $P C R$, a specific pair of primers for a sequence of $120 \mathrm{bp}$ from kDNA minicircle, common to all leishmanias species, was used. The product of PCR was used for DNA sequencing and for RFLP with the enzyme Hae III. The analysis of the restriction pattern was compared to the cultures of $L$. (L.) amazonensis and L. (V.) braziliensis.

RESULTS - The predominant sex was male (75\%), the white color (80\%) and urban professional occupation (48\%). The age varied from 3 to 77 years, with prevalence from 21 to 50 years (56.5\%). In relation to the origin, $65.8 \%$ was from the state of São Paulo, being the cutaneous form the more prevalent (79.6\%). MR was positive in $73.4 \%$ and there was presence of leishmania in 30.6\% of the samples, while IIF presented $59.7 \%$ of positivity. PCR was positive in 81.6\% of skin samples, and PCR-RFLP identified L. (V.) braziliensis (66\%) as predominant species, fact that also happened with DNA sequencing, with $64.4 \%$ of the positive results for L. (V.) braziliensis. Comparing PCR-RFLP and DNA sequencing there was $61 \%$ of agreement amongst the results, being significant in PCR-RFLP for L. (V) braziliensis. CONCLUSION - MR and PCR were equivalent as subsidiary methods for the diagnosis of ATL, such as PCR-RFLP and DNA sequencing in the identification of the leishmania species. On the other hand, the method PCR-RFLP presented smaller cost and smaller time of execution compared to the sequencing of DNA.

Keywords: DNA; Leishmaniasis; Polymerase chain reaction
\end{abstract}

\footnotetext{
"Trabalho realizado na Divisão de Dermatologia, Departamento de Clínica Médica, Faculdade de Medicina de Ribeirão Preto - Universidade de São Paulo (SP) Brasil e Faculdade de Ciências Médicas, Universidade de Pernambuco (PE), Brasil.

MD, mestre em Clínica Médica, FMRP-USP - São Paulo (SP), Brasil

Bióloga, Laboratório de Biologia Molecular, Departamento de Clínica Médica, Faculdade de Medicina de Ribeirão Preto - Universidade de São Paulo - FMRP-USP - Ribeirão Preto (SP), Brasil

Aluna de doutorado, Programa Clínica Médica, Área Investigação Biomédica, FMRP-USP - São Paulo (SP), Brasil

MD, PhD, FCM-UPE - Pernambuco (PE), Brasil

MD, PhD, professora-associada, Divisão de Dermatologia, Departamento de Clínica Médica, FMRP-USP - São Paulo (SP), Brasil 


\section{INTRODUÇÃO}

As leishmanioses encontram-se entre as doenças infectoparasitárias de maior incidência no mundo. Segundo a OMS, mais de 12 milhões de pessoas em 88 países encontram-se doentes, com cerca de 350 milhões de pessoas sob risco de adoecer. Estima-se que a incidência anual seja de 1-1,5 milhão de casos de leishmaniose cutânea e 500.000 casos de leishmaniose visceral. ${ }^{1}$

A leishmaniose tegumentar americana (LTA) é definida como doença infecciosa, crônica, não contagiosa, caracterizada pelo comprometimento da pele, mucosa e cartilagens. Pode manifestar-se como leishmaniose cutânea localizada (LCL), leishmaniose cutânea difusa (LCD), leishmaniose cutâneo-mucosa (LCM), leishmaniose recidivante (LR) e, recentemente, propuseram a expressão "leishmaniose cutânea disseminada borderline" como forma intermediária entre a LCL e os pólos extremos patogênicos LCM e LCD. ${ }^{2}$

O diagnóstico da LTA, de ambas as formas, cutânea e mucosa, é eminentemente clínico, sendo associado a métodos subsidiários, como: pesquisa direta em material de raspado ou punção aspirativa da lesão, corado pelo método de Giemsa ou Leishman, exame histopatológico (HE) de biópsia de lesão, intradermorreção de Montenegro (IRM) e reação de imunofluorescência indireta (Rifi) ${ }^{1,2}$

Com o avanço das técnicas de biologia molecular, a PCR (polymerase chain reaction) tem sido utilizada com sucesso no diagnóstico da LTA, mostrando alta sensibilidade e especificidade ${ }^{3-6}$ Utilizando DNA de leishmania obtido de produtos de PCR, tem sido realizado o seqüenciamento desse DNA, para identificação e caracterização genômica das espécies de leishmanias, tendo sido identificadas, na região nordeste do Estado de São Paulo, as espécies L. (V.) braziliensis e $L$. (L.) amazonensis. ${ }^{\top}$

Mais recentemente, pelo método PCR-RFLP (PCR-restriction fragment lenght polymorphism), empregando-se enzimas de restrição nas amostras cujos exames de PCR foram positivos, é possível identificar as espécies $L$. (V.) braziliensis e $L$. (L.) amazonensis, de forma mais rápida e econômica, sem a necessidade de realizar o seqüenciamento, porém, com iguais segurança e eficácia. ${ }^{8-10}$

\section{CASUÍSTICA E MÉTODOS}

Foi realizado levantamento dos prontuários de 152 pacientes com diagnóstico confirmado de LTA, atendidos no Hospital das Clínicas da Faculdade de Medicina de Ribeirão Preto, Universidade de São Paulo (HC-FMRP-USP), no período de 1993 a junho de 2004, tendo como critério de inclusão ter sido realizada PCR em amostras cutâneo-mucosas.

Os critérios utilizados para definição dos casos de LTA foram: o diagnóstico clinicoepidemiológico, a intradermorreação de Montenegro (IRM) igual ou superior a $5 \mathrm{~mm}$ de induração, o exame histopatológico de amostra de pele ou de mucosa compatível com LTA ou com a presença de amastigotas, e a reação sorológica de imunofluorescência indireta (Rifi) para LTA igual ou superior a $1 / 8$. A esses critérios, somouse o resultado da PCR para pesquisa de leishmania realizada em amostras de pele ou de mucosa com os primers antisense com 25bp e sense com 20bp $\left(\right.$ Nutrachem $^{\mathrm{TM}}$ ), segundo protocolo já estabelecido. ${ }^{5,11}$

Os resultados do seqüenciamento do DNA utilizados para o presente trabalho foram levantados da tese de doutorado de um dos autores, realizada previamente com 102 das 152 amostras ora analisadas, no mesmo laboratório de pesquisa. ${ }^{7}$

A PCR-RFLP foi realizada nas amostras de PCR positivas dos pacientes, pela digestão dos produtos da PCR com a enzima Hae III (modificado de Volpini et al. $^{10}$ ) e comparando-as com culturas de $L$. (V.) braziliensis e L. (L.) amazonenesis. Para os resultados compatíveis com $L$. (V.) braziliensis, observou-se a formação de duas bandas, de 80 e $40 \mathrm{bp}$, fato esse que não ocorre com os resultados compatíveis $\operatorname{com} L$. (L.) amazonenesis, quando o material não é digerido, havendo a permanência do fragmento de 120bp. Para aquelas amostras com bandas diferentes das culturas, optou-se por denominá-las $L$. spp.

Para o estudo estatístico, foram realizados: teste de McNemar ou teste binomial para a comparação dos resultados da IRM, Rifi e exame histopatológico, com os resultados da PCR, seqüenciamento e da PCR-RFLP.

\section{RESULTADOS}

Dos 152 pacientes com LTA estudados, 114 (75\%) eram do sexo masculino, com relação de 3:1 entre homens e mulheres.

Em relação à procedência, 100 pacientes $(65,8 \%)$ eram do Estado de São Paulo, sendo 98 autóctones de sua região nordeste, e, destes, 26 moradores do Município de Ribeirão Preto e dois de outras cidades do estado; 50 pacientes (32,9\%) eram de outros estados (Minas Gerais principalmente), e para dois pacientes $(1,3 \%)$ esse dado era ignorado.

Quanto à cor da pele, 123 pacientes (81\%) eram brancos, $20(13,1 \%)$ eram pardos, sete $(4,6 \%)$ eram negros, e para dois pacientes $(1,3 \%)$ esse dado era ignorado.

Quando se avaliou a ocupação profissional, 44 $(28,9 \%)$ eram de ocupação rural, 73 (48\%) de ocupação urbana, nove $(5,9 \%)$ do lar, cinco $(3,3 \%)$ estudantes, dois $(1,4 \%)$ menores, $11(7,2 \%)$ aposentados, um $(0,7 \%)$ desempregado, e de sete $(4,6 \%)$ pacientes esse 
dado era ignorado.

A forma cutânea acometeu 121 pacientes (79,6\%), as cutâneo-mucosa e mucosa, 30 pacientes $(19,7 \%)$ e, para um paciente $(0,7 \%)$, esse dado foi omitido.

Na amostra estudada, a idade dos pacientes por ocasião do diagnóstico variou de três a 77 anos, sendo 113 (74,3\%) pacientes entre 21 e 60 anos, 17 $(11,2 \%)$ abaixo dos 21 anos, e $22(14,5 \%)$ acima dos 60 anos.

A IRM foi realizada em 143 pacientes, sendo que para nove pacientes esse dado foi omitido. Assim, 105 pacientes $(73,4 \%)$ apresentaram IRM positiva, e 38 (26,6\%), negativa. Os 115 pacientes com LTA forma cutânea apresentaram 85 (73,9\%) resultados positivos da IRM, contra $30(26,1 \%)$ de resultados negativos. Dos 28 pacientes com LTA forma cutâneomucosa, $20(71,4 \%)$ apresentaram IRM positiva, e oito (28,6\%), negativa (Tabela 1$)$.

Dos 152 pacientes estudados, 147 realizaram exame histopatológico de biópsias de pele ou mucosa (Bc), tendo sido constatada a presença de leishmania em 45 (30,6\%). Destes, 118 apresentavam LTA forma cutânea com 36 (30,5\%) casos positivos, isto é, com presença de leishmania nas biópsias, e 82 (69,5\%) casos negativos, com ausência de leishmanias nas biópsias. Os 29 pacientes com LTA forma cutâneomucosa apresentaram nove $(31 \%)$ casos positivos e 20 (69\%) casos negativos (Tabela 1).

A Rifi foi realizada em amostras de 72 pacientes, tendo sido positiva em 43 (59,7\%) e negativa em 29 (40,3\%). Dos 59 casos de forma cutânea, 37 apresentaram Rifi positiva (62,7\%), e 22 negativa $(37,3 \%)$. Dos 13 casos de forma cutâneo-mucosa, seis $(46,2 \%)$ foram positivos, e sete $(53,8 \%)$ foram negativos para Rifi (Tabela 1).
Em relação à PCR, $124(81,6 \%)$ amostras foram positivas, e $28(18,4 \%)$ negativas. Dos 121 casos de forma cutânea, a PCR foi positiva em $103(85,1 \%)$ e negativa em 18 (14,9\%). Dos 30 casos de forma cutâneo-mucosa, $20(66,6 \%)$ foram positivos, e 10 $(33,4 \%)$ foram negativos (Tabela 1$)$.

$O$ seqüenciamento de DNA do fragmento amplificado pela PCR foi realizado em 102 amostras, com $62(60,8 \%)$ resultados positivos e $40(39,2 \%)$ negativos (Tabela 2). Dos resultados positivos, 40 $(39,2 \%)$ amostras apresentaram a espécie $L$. (V.) braziliensis, $20(19,6 \%)$ a espécie $L$. (L.) amazonensis, uma $(1,0 \%)$ a espécie $L$. guyianensis, e de uma (1\%) não foi possível identificar a espécie ( $L$. spp.).

Dos 152 pacientes da amostra, 150 realizaram PCR-RFLP, com 117 (78\%) resultados positivos e 33 (22\%) negativos (Tabela 2). Dos resultados positivos, $78(52,0 \%)$ apresentaram a espécie $L$. (V.) braziliensis, $16(10,7 \%)$ a espécie $L$. (L.) amazonensis, e em 23 $(15,3 \%)$ a espécie não foi determinada ( $L . s p p$. (Figura 1).

Quando se compararam os resultados da PCRRFLP segundo a procedência do paciente, encontraram-se no Estado de São Paulo 51 casos de $L$. (V.) braziliensis, sete de $L$. (L.) amazonensis, 19 de $L$. spp. e 22 negativos. Em outros estados e países, foram encontrados 26 casos de $L$. (V.) braziliensis, oito de $L$. (L.) amazonensis, quatro de L. spp. e 11 negativos.

Quando se compararam os resultados da PCR aos da IRM, em 143 pacientes, observou-se que: dos $116(81,1 \%)$ pacientes com amostras positivas à PCR, 86 (60\%) tiveram resultado positivo à IRM, e 30 (21\%) tiveram resultado negativo. Dos $27(18,9 \%)$ pacientes com amostras negativas à PCR, $19(13,3 \%)$ tiveram resultado positivo à IRM, e oito $(5,6 \%)$ tiveram resultado negativo, não havendo significância estatística.

TABELA 1: Resultados dos exames subsidiários para o diagnóstico da LTA em relação à forma clínica na amostra estudada, HC-FMRP-USP, 1993 a junho de 2004

\begin{tabular}{lcccccccc}
\hline & \multicolumn{9}{c}{ FORMA CLÍNICA } & \multicolumn{2}{c}{} \\
& \multicolumn{1}{c}{ Cutânea } & \multicolumn{2}{c}{ Cutâneo-mucosa } & \multicolumn{2}{c}{ Ignorada } & \multicolumn{2}{c}{ Total } \\
\hline EXAMES & N. & $\%$ & N. & $\%$ & N. & $\%$ & N. & $\%$ \\
IRM (+) & 85 & 73,9 & 20 & 71,8 & 0 & - & 105 & 73,4 \\
IRM (-) & 30 & 26,1 & 8 & 28,6 & 0 & - & 38 & 26,6 \\
Bc (+) & 36 & 30,5 & 9 & 31 & 0 & - & 45 & 36,7 \\
Bc (-) & 82 & 69,5 & 20 & 69 & 0 & - & 102 & 63,3 \\
Rifi (+) & 37 & 62,7 & 6 & 46,2 & 0 & - & 43 & 59,7 \\
Rifi (-) & 22 & 37,3 & 7 & 53,8 & 0 & - & 29 & 40,3 \\
PCR (+) & 103 & 85,1 & 20 & 66,6 & 1 & - & 124 & 81,6 \\
PCR (-) & 18 & 14,9 & 10 & 33,4 & 0 & - & 28 & 18,4 \\
\hline
\end{tabular}

IRM: Intradermorreação de Montenegro; Bc: Exame histopatológico de biópsia cutâneo-mucosa; Rifi: Reação sorológica de imunofluorescência indireta; PCR: polymerase chain reaction; (+): positivo; (-): negativo 
TABELA 2: Resultados do seqüenciamento de DNA e da PCR-RFLP em amostras de pele e mucosa de pacientes com LTA, HC-FMRP-USP, 1993

a junho de 2004

\begin{tabular}{lccccc}
\hline \multicolumn{4}{c}{ Exame subsidiário } \\
\hline Espécie & Seqüenciamento & \multicolumn{2}{c}{ PCR-RFLP } \\
& N. & $\%$ & N. & $\%$ \\
L. (V.) braziliensis & 40 & 39,2 & 78 & 52 \\
L. (L.) amazonensis & 20 & 19,6 & 16 & 10,7 \\
L. spp & 1 & 1 & 23 & 15,3 \\
L. guyianensis & 1 & 1 & 0 & \\
Negativo & 40 & 39,2 & 33 & 22 \\
\hline Total & 102 & 100 & 150 & 100 \\
\hline
\end{tabular}

Quando se compararam os resultados da PCR aos do exame histopatológico, quanto à presença de leishmania (Bc) em 147 amostras, observou-se que: das 121 (82,3\%) amostras positivas à PCR, 42 (28,6\%) tiveram resultado positivo à $\mathrm{Bc}$, e 79 (53,7\%) tiveram resultado negativo. Das $26(17,7 \%)$ amostras negativas à $\mathrm{PCR}$, três (2\%) tiveram resultado positivo à $\mathrm{Bc}, \mathrm{e}$ $23(15,7 \%)$ tiveram resultado negativo $(p=0,01)$.

Quando se compararam os resultados da PCR aos da reação de imunofluorescência indireta (Rifi) em 72 amostras de pacientes, observou-se que: dos 57 (79,2\%) pacientes com amostras positivas à PCR, $33(45,8 \%)$ tiveram resultado positivo à Rifi, e 24 (33,3\%) tiveram resultado negativo. Dos 15 (20,8\%) pacientes com amostras negativas à PCR, 10 (13,9\%) tiveram resultado positivo à Rifi, e cinco (7\%) tiveram resultado negativo $(\mathrm{p}<0,05)$.

$\mathrm{Na}$ tabela 3 estão registrados os resultados da PCR-RFLP comparados aos do seqüenciamento em 100 amostras, visto que dois pacientes não realizaram a PCR-RFLP, tendo eles apresentado no seqüenciamento um resultado negativo e um $L$. (L.) amazonensis. Com isso, encontrou-se concordância de resultados em 61 (61\%) amostras, isto é, tanto no seqüenciamento como na PCR-RFLP, 33 (33\%) amostras apresentaram como resultado a espécie $L$. (V.) brazilien- sis, nove (9\%) apresentaram a espécie $L$. (L.) amazonenesis, e 19 (19\%) apresentaram resultados negativos. Nos demais, 39 (39\%) amostras, os dados encontrados foram discordantes. Salienta-se que, para a técnica PCR-RFLP, não foi possível a identificação da espécie em 11 amostras (L. spp.).

\section{DISCUSSÃO}

A forma clínica mais encontrada foi a cutânea, com $79,6 \%$ dos casos, seguida pela forma cutâneomucosa, com 19,7\%. Esses dados coincidem com os de outros estudos, como o de Tolezano, ${ }^{12}$ em trabalho realizado no Estado de São Paulo, quando encontrou predomínio da forma cutânea e apenas $23,3 \%$ dos pacientes com a forma mucosa.

A IRM foi positiva em $73,4 \%$ dos pacientes e negativa em $26,6 \%$. Stolf et al. ${ }^{13}$ relataram positividade da IRM em 95\% em surto epidêmico na região de Itaporanga, SP. Follador et al., ${ }^{14}$ em surto epidêmico em Canoa, BA, obtiveram $89,7 \%$ de resultados positivos da IRM. Medeiros et al., ${ }^{5}$ em estudo retrospectivo na região nordeste do Estado de São Paulo, encontraram $88,7 \%$ de resultados positivos na IRM. Os índices de positividades menores encontrados no estudo aqui apresentado podem ser justificados pela grande variabilidade do tempo de evolução da doença (de um mês a 25 anos) e também pela não-padronização do antígeno.

A presença da leishmania em biópsias foi evidenciada em 30,6\% das amostras, sendo 88,9\% dessas na forma cutânea, e 11,1\% na forma cutâneo-mucosa. Em trabalho de revisão, Lucciola et al. ${ }^{15}$ encontraram leishmanias em 30,3\% dos casos. No entanto, em situações de surto epidêmico, como descrito por Stolf et al., ${ }^{13} \mathrm{o}$ achado de leishmanias foi descrito em $84 \%$ dos casos.

A Rifi foi positiva em $59,7 \%$ da amostra dos pacientes avaliados, sendo $86 \%$ na forma cutânea, e $14 \%$ na forma cutâneo-mucosa. Oliveira-Neto et al., ${ }^{16}$ em estudo no Estado do Rio de Janeiro, obtiveram 75\% dos casos com Rifi positiva. Essa diferença de resultados pode ser explicada pela variação do tempo

TABELA 3: Comparação dos resultados do seqüenciamento e da PCR-RFLP, em relação à espécie de Leishmania, em 100 amostras cutâneas ou mucosas de pacientes com LTA, HC-FMRP-USP, 1993 a junho de 2004

\begin{tabular}{|c|c|c|c|c|c|}
\hline \multicolumn{6}{|c|}{ PCR-RFLP } \\
\hline Seqüenciamento & L. (V.) braziliensis & L. (L.) amazonensis & L. spp. & Negativo & Total \\
\hline L. (V.) braziliensis & 33 & 1 & 5 & 1 & 40 \\
\hline L. (L.) amazonensis & 1 & 9 & 6 & 3 & 19 \\
\hline L. $s p p$ & 1 & 0 & 0 & 0 & 1 \\
\hline L. guyanensis & 1 & 0 & 0 & 0 & 1 \\
\hline Negativo & 14 & 3 & 3 & 19 & 39 \\
\hline Total & 50 & 13 & 14 & 23 & 100 \\
\hline
\end{tabular}




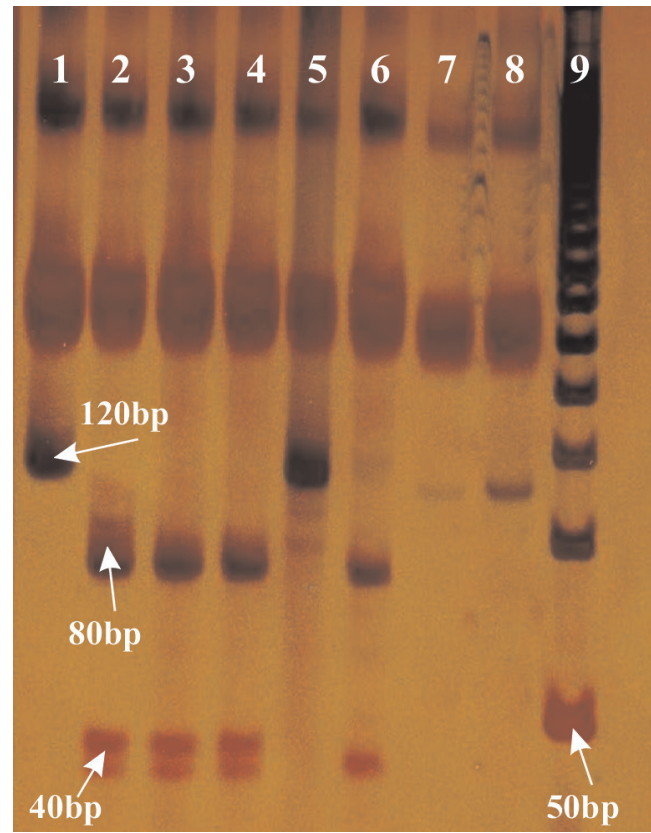

Figura 1: Análise do padrão de restrição por digestão da enzima Hae III de produtos amplificados por PCR para identificação de Leishmania em gel de acrilamida $10 \%$ não desnaturante. Colunas: 1: amostra de cultura de $L$. (L.) amazonensis (IFLA/BR/67/PH8) (seta: 120bp). 2: amostra de cultura de L. (V) braziliensis (Lbb 2903) (seta: 80 e 40bp). 3-8: amostras de pele de pacientes com LTA. 9: marcador de PM Ladder 50 bp

de evolução da doença na amostra aqui analisada.

O exame da PCR foi positivo em 81,6\% dos pacientes. Avaliando os resultados da PCR em relação à forma, encontraram-se $85,1 \%$ dos casos positivos na forma cutânea e $66,6 \%$ dos casos positivos na forma cutâneo-mucosa. Pirmez et al., ${ }^{3}$ em estudo realizado no Estado do Rio de Janeiro, obtiveram resultados positivos de PCR em 94\% dos casos, IRM positiva em 98\% e presença de leishmania em $62 \%$ dos casos. Medeiros et al., ${ }^{5}$ em trabalho realizado no nordeste do Estado de São Paulo, encontraram 81,5\% de resultados positivos da PCR, $88,7 \%$ da IRM e 50\% do exame histopatológico. Oliveira et al., ${ }^{6}$ em trabalho realizado na Bahia, encontraram resultados positivos de PCR em 100\% dos casos, IRM em $72 \%$ (os casos negativos tinham menos de 55 dias de evolução da doença), tendo todos os pacientes sido avaliados com quatro meses ou menos de evolução.

Os nossos resultados de PCR são inferiores aos da literatura, muito provavelmente pelo fato de esta amostra incluir casos com longa data de evolução da doença (14 pacientes com mais de três anos de evolução, e sete com mais de 10 anos de evolução), circunstância não evidenciada nos trabalhos relatados acima, e também por esses trabalhos terem sido realizados em áreas endêmicas, quando a PCR é realizada em amostras de casos de curta evolução, tendo maior possibilidade de ser positiva. Acrescido a esse fato, somam-se os $19,7 \%$ de casos de LTA forma cutâneomucosa na amostra estudada, contribuindo para a menor positividade da PCR, quando comparada aos dados da literatura.

Com a realização da PCR-RFLP nas amostras amplificadas por PCR, foram encontrados $52 \%$ de resultados positivos para a espécie $L$. (V.) braziliensis, $10,7 \%$ para $L$. (L.) amazonensis, $15,3 \%$ para $L$. spp., e $22 \%$ de resultados negativos. Ao serem excluídas as amostras, cuja PCR foi negativa, a positividade da PCR-RFLP, quanto à identificação da espécie, aumenta para $78 \%$.

Em trabalho realizado em Belo Horizonte, com 66 pacientes portadores de LTA e utilizando resultados positivos de PCR, Volpini et al. ${ }^{10}$ constataram que $91 \%$ destes pacientes apresentaram resultados positivos para a espécie $L$. (V.) braziliensis, e 9\% para $L$. (L.) amazonensis. Nos resultados aqui apresentados, os autores encontraram valores pouco maiores para a espécie $L$. (L.) amazonensis, devido aos pacientes procedentes de outros estados, que contribuíram com $50 \%$ dos casos dessa espécie, e pelo fato de que, em 23 amostras estudadas, a identificação pela enzima Hae III não foi possível, mesmo após várias tentativas.

O seqüenciamento evidenciou $39,2 \%$ de casos para a espécie $L$. (V.) braziliensis, $19,6 \%$ para $L$. (L.) amazonensis, $1 \%$ para L. spp., 0,9\% para L. guyianensis e $39,2 \%$ de resultados negativos. Os resultados negativos devem-se ao fato de os sequenciamentos não terem sido reconhecidos por seqüências catalogadas no gene bank por ocasião dos experimentos.

Quando compararam o seqüenciamento com a PCR-RFLP, excluindo os resultados negativos e não realizados, os autores obtiveram concordância de positividade em $75 \%$ para $L$. (V.) braziliensis e $20,4 \%$ para $L$. (L.) amazonensis, na amostra estudada. Ao serem consideradas as espécies separadamente, a PCR-RFLP mostrou-se superior para a identificação de L. (V.) braziliensis. Cabe ressaltar que os experimentos foram realizados em épocas diferentes, isto é, os resultados do seqüenciamento antecederam os experimentos da PCR-RFLP, prejudicando a análise dos resultados. O ideal seria uma única pessoa proceder simultaneamente ambos os experimentos.

$\mathrm{Na}$ literatura consultada, não foram encontrados trabalhos comparando esses métodos no diagnóstico de LTA.

\section{CONCLUSÕES}

$\mathrm{Na}$ amostra estudada, de 152 pacientes com LTA, houve predomínio do sexo masculino, na faixa etária de 21 a 50 anos e da forma clínica cutânea $(79,6 \%)$. 
A PCR mostrou-se superior, em relação à IRM, ao exame histopatológico e à Rifi, na detecção dos casos de LTA, porém não houve significância estatística quando comparada à IRM.

O seqüenciamento evidenciou $39,2 \%$ de casos para a espécie $L$. (V.) braziliensis, $19,6 \%$ para $L$. (L.) amazonensis, $1 \%$ para L. spp., $1 \%$ para L. guyianensis e $39,2 \%$ de resultados não identificados.

A PCR-RFLP identificou as espécies $L$. (V.) braziliensis em 52\% das amostras, L. amazonenesis em $10,7 \%, L . s p p$. em $15,3 \%$, e $22 \%$ de resultados negativos. Quando se comparou o seqüenciamento à PCR-RFLP, excluindo os resultados negativos e não identificados,

\section{REFERÊNCIAS}

1. Davies CR, Kaye P, Croft SL, Sundar S. Leishmaniasis: new approaches to disease control. BMJ. 2003; 326: 377-82.

2. Silveira FT, Lainson R, Corbett CEP. Clinical and immunopathological spectrum of American Cutaneous Leishmaniasis with special reference to the disease in Amazonian Brazil - A review. Mem Inst Oswaldo Cruz. 2004; 99: 239-51.

3. Pirmez C, Trajano VS, Oliveira-Neto MP, Cruz AM, Costa SCG, Catanho M, et al. Use of PCR in diagnosis of human American tegumentary leishmaniasis in Rio de Janeiro, Brazil. J Clin Microbiol. 1999; 37: 1819-23.

4. Andrade ASR, Gomes RF, Fernandes O, Melo MN. Use of DNA-based diagnostic methods for human leishmaniasis in Minas Gerais, Brasil. Acta Trop. 2001; 781: 261-7.

5. Medeiros ACR, Rodrigues SS, Roselino AMF. Comparison of the specificity of PCR and histopathological detection of Leishmania for the diagnosis of American cutaneous leishmaniasis. Braz J Med Res. 2002; 35: 421-4.

6. Oliveira CI, Báfica A, Oliveira F, Favali CBF, Correa T, Freitas LAR, et al. Clinical utility of polymerase chain reaction-based detection of Leishmania in diagnosis of American Cutaneous Leishmaniasis. Clin Infect Dis. 2003; 37: 149-53

7. Medeiros ACR. Análise filogenética das espécies de Leishmania implicadas na Leishmaniose Tegumentar Americana em pacientes atendidos no Hospital das Clínicas da Faculdade de Medicina de Ribeirão Preto da Universidade de São Paulo. [tese]. Ribeirão Preto: Universidade de São Paulo; 2002.

8. Marfurt J, Nasereddin A, Niedwieser I, Jaffe CL, Beck HP, Felger I. Identification and differentiation of Leishmania species in clinical samples by PCR amplification of the miniexon sequence and subsequent restriction fragment length polymorphism analysis. J Clin Microbiol. 2003; 41:3147-53.

9. Marfurt J, Niederwieser I, Makia ND, Beck HP, Felger I. Diagnostic genotyping of Old and New World Leishmania species by PCR-RFLP. Diag Microbiol Inf Dis. 2003; 46: 115-24.

10. Volpini AC, Passos VMA, Oliveira GC, Romanha AJ. PCR-RFLP to identify Leishmania (Viannia) braziliensis e obteve-se concordância em $75 \%$ dos casos para $L$. (V.) braziliensis e em 20,4\% para L. (L.) amazonensis.

Os exames subsidiários - seqüenciamento de DNA e PCR-RFLP - mostraram-se equivalentes para a tipagem de leishmania em amostras de pele ou de mucosa, lembrando-se que o último apresenta menores custo e tempo de execução.

\section{AGRADECIMENTO}

Suporte financeiro: FAEPA (Fundação de Amparo ao Ensino, Pesquisa e Assistência)
L. (Leishmania) amazonensis causing American cutaneous leishmaniasis. Acta Trop. 2004; 90: 31-7.

11. Rodrigues EHG, de Brito MAF, Mendonça MG, Werkhäuser RP, Coutinho EM, Souza WV, et al. Evaluation of PCR for diagnosis of American Cutaneous Leishmaiasis in an area of endemicity in Northeastern Brazil. J Cli. Microbiol. 2002; 3572-6.

12. Tolezano JE. Ecoepidemiological aspects of American cutaneous leishmaniasis in the state of São Paulo, Brazil. Mem Inst Oswaldo Cruz. 1994; 89: 427-34.

13. Stolf HO, Marques AS, Marques MEA, Yoshida ELA, Dillon NL. Surto de leishmaniose tegumentar Americana em Itaporanga, São Paulo (Brasil). Rev Inst Med Trop São Paulo. 1993; 35: 437-42.

14. Follador I, Araújo C, Cardoso MA, Tavares-Neto J, Barral A, Miranda JC, Bittencourt A, Carvalho EM. Surto de leishmaniose tegumentar americana em Canoa, Santo Amaro, Bahia, Brasil. Rev Soc Bras Med Trop São Paulo. 1999; 32: 497-503.

15. Lucciola GV, Passos VM de A, Patrus OA. Mudança no padrão epidemiológico da leishmaniose tegumentar americana. An Bras Dermatol. 1996; 71: 99-105.

16. Oliveira-Neto MP, Mattos MS, Perez MA, da Cruz AM, Fernandes O, Moreira J, et al. American tegumentary lieshmaniasis (ATL) in Rio de Janeiro State, Brazil: main clinical and epidemiologic characteristics. Int J Dermatol. 2000; 39: 506-14.

\footnotetext{
ENDEREÇO PARA CORRESPONDÊNCIA: Ana Maria F. Roselino Professora Associada - Faculdade de Medicina de Ribeirão Preto - Divisão de Dermatologia Departamento de Clínica Médica Av. Bandeirantes, 3900 14049-900 - Ribeirão Preto - SP Tel: (16)3633-0236 / 2715 Fax: (16)3633-6695 E-mail: amfrosel@fmrp.usp.br
} 